\title{
Lateral
}

Journal of the Cultural Studies Association

\section{Cultural Studies in the Interregnum}

\author{
by Robert F. Carley, Stefanie A. Jones, Eero Laine and Chris Alen Sula \\ I Issue 9.2 (Fall 2020)
}

\begin{abstract}
This issue of Lateral contributes to a number of ongoing questions and conversations. In it, we see a range of methodologies that span particular sites, take up theoretical debates, and cross borders and boundaries, both political and cultural. The work of this issue sits in conversation with the present moment, even as it at times draws on and excavates the past. 2020 has seemed to both accelerate and extend a number of ongoing crises and emergencies that have defined the decade. Contributors to this issue are working in and through this gap. Many new structures, including a new structure of feeling, are ascendant, and the task of contemporary cultural studies is clear: thinking and theorizing the interregnum will define the work of the present conjuncture.
\end{abstract}

KEYWORDS cultural studies

Cultural studies, today, is a field that offers radical possibilities: it is a locus for theories of politicized and socialized commons; it provides a venue for rethinking the role of culture and political organizations including the political party; it finds seeds of revolutionary fervor bursting out of visual spaces. Cultural studies has identified and explored the emergence of new theoretical conversations in settler colonialism, new materialism, disability studies, and neo-institutionality. And cultural studies is in a constant dialogue with itself, reflecting a self-referentiality that spans its history and the contemporary moment. Cultural studies of today has expanded and deepened intersectionality in its various articulations and disarticulations, enriching the thought that demonstrates the changing (and changing-same) shape of relations between race, class, and capital. Such work is evident in the pages of Lateral, and editors and authors alike have labored to produce the means, relations, and spaces-virtual and real-that reflect the projects and the politics that comprise the field.

Across cultural studies' relatively short history it has, in the immediate post-war period, used close reading to constitute-for the first time-working class life as culture; as complex, artefactual, and rich in its varieties of meaning and practice. In the 1970s it placed discourse analysis of media and politics in conversation with statistical data to paint a picture of the nascent neoliberal state's response to race and migration, making cultural studies seem almost prophetic. Contemporary cultural studies thrives due to an open-door policy to various methods, theories, and objects of study that can help it locate tensions and contradictions as they are made manifest. For Lateral, cultural studies is more than multi-methodological. Cultural studies finds common cause with the various fields and disciplines that are concerned with the production of the contemporary moment whether they be humanistic, social-scientific, or, at times, outside of liberal arts proper.

It is our hope for Lateral to become more uniquely poised to evaluate and appraise cultural studies' orientation towards the contemporary and, indeed, the future. Lateral's life-span 
covers the last decade, and in that time that it has developed into one of a handful of pulse-points for cultural studies; it is a place one visits if they want to understand what cultural studies has been (Years in Cultural Studies < https://csalateral.org/years > project), where it is (our regular articles < https://csalateral.org/archive >, book reviews < https://csalateral.org/reviews $>$ ), and how it is developing (Forums $<$ https://csalateral.org/forums $>$ ) through the economic and financial crisis that followed 2008 , during the course of the last four years, and in the interim.

The economic, political, environmental, and social patterns of this period, highlighted recently in the US response to the coronavirus, raises the specter of an interregnum. In an often cited passage, Antonio Gramsci says, "The crisis consists precisely in the fact that the old is dying and the new cannot be born; in this interregnum a great variety of morbid symptoms appear."1 Gramsci refers to periods where a relatively strong stability, a powerful bloc of interests, or, even, a hegemony (signifying the predominance of a particular ideology) is waning and nothing has emerged on the horizon. It is a borrowed term that refers to a cessation of rule or governance between reigns, regimes, or administrations. Framing this period as an interregnum suggests political opportunities, but does not define who may take advantage of these opportunities. In fact, it clearly indicates the flourishing of disturbing, abnormal, and monstrous symptoms. In certain ways, fascism already organizes to take advantage of these instabilities,,-2 and the left will remain disorganized at its own peril.

In no small part, the political projects, critical pedagogy, and scholarly and intellectual practices of cultural studies define and distinguish it from other commitments of thought and intellectual practice today. As we close out our first decade with this final issue of 2020, Lateral moves more firmly toward explicating the interregnum, reflecting on how the journal lays the groundwork for contextualizing the present in light of the last ten years. What has happened in the most recent decade that has brought us to precisely where we are today? And how have these events been taken up, critiqued, and transformed by cultural studies?

The past ten years have shown us that global economic, financial, and environmental crises are increasingly common, reiterating as the condition of racial capitalism rather than its exceptions. Devastating storms, temperature records, and natural disasters are yearly occurrences, exacerbating the persistent and destabilizing effects of poverty and conflict in, for example, the US, South America, and the Middle East and Africa, especially Syria, Iran, and Turkey. Planetary movements from below have shaped not only contemporary policy and politics but the ways that politics are practiced: the Indignados; Occupy Wall Street; Antifa; Indigenous environmental justice movements including against drilling, fracking, and pipelines; Gilets Jaunes; the record-setting 2020 Indian farmers' strikes; and global movements against trans and queer oppression; along with the many manifestations of the Movement for Black Lives, especially Trans Black Lives Matter. These changes exist amidst rapidly escalating pseudo-populist movements that span and overlap regional, national, and international interests and populations. The self-proclaimed "alt-right" and neo-facist, neo-Nazi, and white supremicist groups are bolstered and encouraged by proto-fascist parties and political leaders from Trump to Modi to Bolsonaro to Duarte as we witness the end of the "Pink Wave" in Latin America and the rise of conservative and reactionary figures and cohorts. Our most recent decade has produced a sui generis response to the crises that mark this interregnum. Cultural studies is a field that is best poised to address what Stuart Hall has referred to as the culture-society couplet in the present. 3 How do we do cultural studies in an interregnum? 
In the lead article of this issue, "From Gwangju to Brixton: The Impossible Translation of Han Kang's Human Acts," < https://csalateral.org/issue/9-2/from-gwangju-to-brixtonimpossible-translation-han-kang-human-acts-pak/> Yumi Pak holds together two disparate conversations that exemplify the possibilities for cultural studies today. The first focuses on tensions between autobiography and fiction within Black literary traditions, and the other on unsettling widely-held narratives of the United States as savior figure in the Korean War. In the interstice, Pak offers a sprawling cultural geography in narrative form: a diasporic memory work, or an autohistoria-teoría-"a personal essay that theorizes"—on Han Kang's novel Human Acts. Pak's theoretically robust and riveting narrative account of what brought her to "do something" with Kang's Human Acts is a unique act of poesis. It pulls together the personal, theoretical, historical, and cultural across geographic and racial boundaries in ways that scholarship in cultural studies often can and does not.

In Lateral 8.1, AK Thompson < https://csalateral.org/issue/8-1/when-shock-is-no-longershocking-benjamins-dialectical-image-thompson/> showed how Benjamin's conception of shock in the context of the dialectical image might be saved by strategies of epistemological seduction that operate, not to substitute shock, but rather as a concrete strategy for revitalizing our capacity to experience it. This issue features Thompson's article "How to Do Things with Walter Benjamin." < https://csalateral.org/issue/9-2/howto-do-things-with-walter-benjamin-thompson/> Thompson points out that although Benjamin is now a common reference point within cultural studies, no one has tried to build upon his contributions by operationalizing his broader intellectual project-a project developed in part across texts like "The Artist as Producer," "The Work of Art in the Age of Mechanical Reproduction," the Passagenwerk, and The Arcades Project. Drawing on these as well as a broader range of texts, Thompson argues for, shows, and further develops Benjamin's approach, to the methodological benefit of cultural studies scholars today.

In "Border Trash: Recovering the Waste of US-Mexico Border Policy in Fatal Migrations and 2666," < https://csalateral.org/issue/9-2/border-trash-us-mexico-policy-fatal-migrations2666-quintanilla/> Alyssa Quintanilla continues conversations about the relationship between the legal, economic, and ideological infrastructures that shape the US-Mexico border. Through analysis of Robert Bolaño's novel 2666 and Josh Begley's digital art installation Fatal Migrations, Quintanilla reveals how these artists challenge the deployment of discourses of environmentalism and waste disposal that facilitate the dehumanization at the heart of deaths around the border. By linking femicides on the southern side of the border with the deaths of migrants headed north, Quintanilla illuminates how the patriarchy, capitalism, and imperialism extend beyond state boundaries to shape spaces and lives.

The question of where something comes from often uncovers more than just a neat origin story. Shantam Goyal's "Sounds from Nowhere: Reading Around Raga-Jazz Style" < https://csalateral.org/issue/9-2/sounds-from-nowhere-reading-around-raga-jazz-stylegoyal/> traces political and artistic interchange across continents and artists, uncovering the work and influence of Shankar-Jaikishan. Goyal reconsiders the specificity of the album in light of the markets of music and colonial histories. In doing so, Goyal offers us a way of reading the past through a particular piece of art that encapsulates and crystalizes modes of exchange and influence.

Finally, this issue features Ashvin Kini's essay, "Political Blackness, British Cinema, and the Queer Politics of Memory." < https://csalateral.org/issue/9-2/political-blackness-britishcinema-and-the-queer-politics-of-memory/> Kini explores "political Blackness" (originally 
a coalitional antiracist politics in England in the 1970s and 1980s) as a queer feminist politics based on multiple, nonequivalent histories of gendered racialization. In doing so, the author more than queers political Blackness; rather, Kini's reading renews the concept for contemporary cultural theorists and critics. Kini provides readers with an interpretive practice that queers the politics of racial representation as a multi-faceted haunting that locates the literal and metaphorical specters of the British empire in contemporary texts. Kini's work develops political Blackness beyond the faultlines, or ruptures, that queer and feminist challenges proffered to both the concept and the political strategy from decades before.

As a whole, this issue of Lateral contributes to a number of ongoing questions and conversations. In it, we see a range of methodologies that span particular sites, take up theoretical debates, and cross borders and boundaries, both political and cultural. The work of this issue sits in conversation with the present moment, even as it at times draws on and excavates the past. 2020 has seemed to both accelerate and extend a number of ongoing crises and emergencies that have defined the decade. Contributors to this issue are working in and through this gap. Many new structures, including a new structure of feeling, are ascendant, and the task of contemporary cultural studies is clear: thinking and theorizing the interregnum will define the work of the present conjuncture.

\title{
Notes
}

1. Antonio Gramsci, Selections from the Prison Notebooks, (New York: International Publishers, 1971), p. 276. D

2. Naomi Klein, The Shock Doctrine: The Rise of Disaster Capitalism (New York: Picador, 2007).

3. Colin MacCabe, "An Interview With Stuart Hall, December 2007." Critical Quarterly, 50, no. 1-2 (2008 Spring-Summer).

\section{Author Information}

\author{
Robert F. Carley \\ Robert F. Carley is Associate Professor of International Studies at Texas A\&M \\ University, College Station. \\ View all of Robert F. Carley's articles.
}

\section{Stefanie A. Jones}

SAJ is a McNair scholar, an organizer, and an educator, and received their doctorate from the Graduate Center of the City University of New York. SAJ has published in edited collections and Theatre Journal and has taught at Brooklyn College, Hunter College, the College of Staten Island, Marymount Manhattan College, and New York University. SAJ's research explores policing, war, white 
supremacy, twenty-first century capitalist economies, gender, disability, and the connections between class formation and political practice.

View all of Stefanie A. Jones's articles.

\section{Eero Laine}

Eero Laine is an Assistant Professor at the University at Buffalo, State University of New York.

View all of Eero Laine's articles.

\section{Chris Alen Sula}

Chris Alen Sula is Associate Professor at Pratt Institute's School of Information. His research explores the digital humanities as a field, including curricula, the early history of $\mathrm{DH}$, and disciplinarity. He has also published on citation studies in the humanities, the politics of technology, and ethical uses of data and visualization.

View all of Chris Alen Sula's articles.

\section{Article details}

Robert Carley, Stephanie A. Jones, Eero Laine, and Chris Alen Sula, "Cultural Studies in the Interregnum," Lateral 9.2 (2020).

https://doi.org/10.25158/L9.2.1

This content is licensed under a Creative Commons Attribution-NonCommercial 4.0 International License. Copyright is retained by authors.

Lateral is the peer-reviewed, open access journal of the Cultural Studies Association.

ISSN 2469-4053 